Research Paper

\title{
FAM83D, a microtubule-associated protein, promotes tumor growth and progression of human gastric cancer
}

\author{
Minlu Huang ${ }^{1}$, Xinjie Ma ${ }^{1}$, Hongpeng Shi ${ }^{1}$, Lei Hu ${ }^{1}$, Zhiyuan Fan ${ }^{1}$, Li Pang ${ }^{1}$, Fan \\ Zhu $^{1}$, Xiao Yang ${ }^{1}$, Wei Xud ${ }^{1}$, Binya Liu ${ }^{1}$, Zhenggang Zhu ${ }^{1}$ and Chen $\mathbf{L i}^{1}$ \\ ${ }^{1}$ Shanghai Key Laboratory of Gastric Neoplasms, Department of Surgery, Shanghai Institute of Digestive Surgery, Ruijin
Hospital, Shanghai Jiao Tong University School of Medicine, Shanghai 200025, People's Republic of China
}

Correspondence to: Chen Li, email: leedoctor@sina.com

Keywords: FAM83D, gastric cancer, proliferation, HMMR, TPX2

Received: August 17, $2016 \quad$ Accepted: June 02, $2017 \quad$ Published: August 10, 2017

Copyright: Huang et al. This is an open-access article distributed under the terms of the Creative Commons Attribution License 3.0 (CC BY 3.0), which permits unrestricted use, distribution, and reproduction in any medium, provided the original author and source are credited.

\section{ABSTRACT}

FAM83D, a microtubule-associated protein (MAP), is overexpressed in diverse types of human cancer. The expression and critical role of FAM83D in human gastric cancer (GC), however, remains largely unknown. Here, we conducted molecular, cellular and clinical analyses to evaluate the functional link of FAM83D to GC. FAM83D expression was elevated in gastric tumors, and its expression strongly correlated with lymph node metastasis and TNM stage. In addition, over-expression of FAM83D in GC cell lines enhanced cell proliferation, cycle progression, migration, invasion, as well as tumor growth and metastatic dissemination in vivo. Furthermore, FAM83D exhibited a strong cell cycle correlated expression. The knockdown of FAM83D inhibited the regrowth of microtubules in GC cells. FAM83D was co-immunoprecipitated with HMMR, TPX2, and AURKA, a set of drivers of mitosis progression. Taken together, our results demonstrate FAM83D as an important player in the development of human gastric cancer, and as a potential therapeutic target for the treatment of cancer.

\section{INTRODUCTION}

Gastric cancer (GC) is one of the leading causes of cancer-related death worldwide [1-3]. The current treatment of this disease, however, is still largely relying on the surgical removal and/or chemotherapies due to a shortage of target therapies. Thus, understanding how GC is regulated at genetic, molecular and signaling levels will provide promising targets for the development of novel therapeutic agents to improve current treatment.

Recently, Family with sequence similarity 83 member D (FAM83D), also known as C20Orf129 or CHICA, has been implicated as a crucial player in the GC malignancy. This gene was initially identified as a novel spindle component by mass-spectrometry [4]. It contains a highly conserved domain, DUF1669, which is critical for CRAF binding and activation of MAPK signaling [5, 6]. In addition, FAM $83 D$ is situated at a cancer-susceptible chromosomal locus (20q), which is frequently amplified in a variety of human cancers, including gastric cancer
[7-9]. Also, FAM83D is elevated at the protein level in human tumor tissues and is associated with poor prognosis in breast cancer and hepatocellular carcinoma $[10,6,11$, 12]. In addition, FAM $83 D$ is implicated in promoting tumor cell proliferation, migration, and invasion through activation of the mTOR- and MAPK- signaling pathway $[6,10]$. These observations implicate $F A M 83 D$ as a strong driver of tumor development and progression in human cancer.

FAM83D protein localizes to the cytoplasm during interphase and to the spindle microtubules and poles during mitosis [4, 13] (Figure 1A). It is increased and phosphorylated upon cell upon entering the G2/M phase $[13,14]$, indicating its dynamic mitotic function. In line with these observations, the depletion of FAM83D impairs chromosomes aggregation on the metaphase plate and the nuclear envelope breakdown (NEBD), thereby delaying the onset of anaphase during mitosis [13, 15]. Also, FAM $83 D$ appears to be concomitantly decreased with a group of mitosis-related genes (PLK1, CDC25B, BUB1B, 
and Cyclin-F) by MiR-210 [16]. Furthermore, FAM83D is overexpressed in primary tumors carrying TP53 mutations, compared to those with intact TP53 $[12,17]$. Together, these lines of evidence suggest that FAM $83 D$ impacts tumor cell proliferation or growth by controlling cell cycle progression.

At the molecular level, FAM83D appears to form a complex with DYNLL1 and HMMR, promoting proper mitotic spindle orientation, rather than directly impacting on astral microtubules [15]. In particular, HMMR, a cell surface hyaluronan receptor and mitotic spindle protein and the driver of tumor progression [18], has been implicated in the targeting of FAM83D to the mitotic spindle $[15,19]$. It also appears to regulate function and mitotic location of TPX2 [19, 20], which is essential for targeting AURKA to the spindle [21, 22]. Furthermore, TPX2 (c20orf1), the targeting protein for Xklp2, regulates the organization of MTs [23]. Inhibition of HMMR or TPX2 severely impairs mitotic spindle assembly and integrity [20, 24-28]. Also, Aurora-A, known as Aurora kinase A (AURKA), promotes tumorigenesis by affecting cell cycle progression [29]. In particular,

A
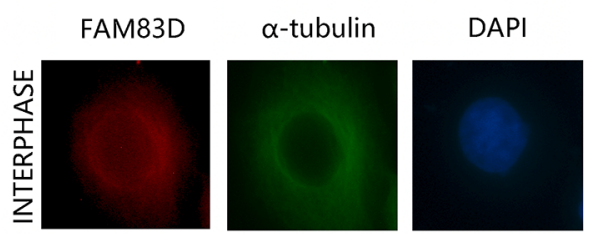

MERGE
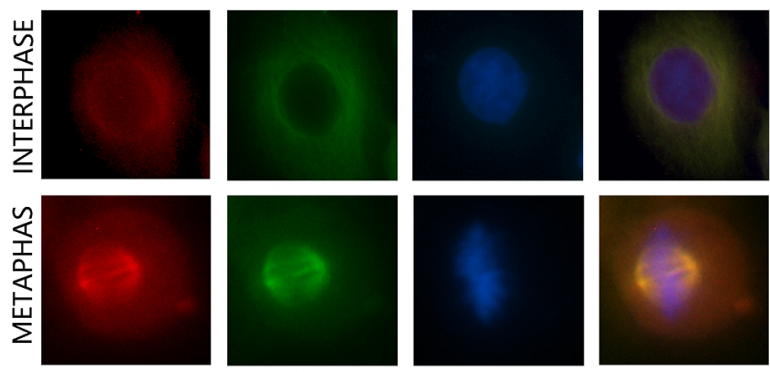

B

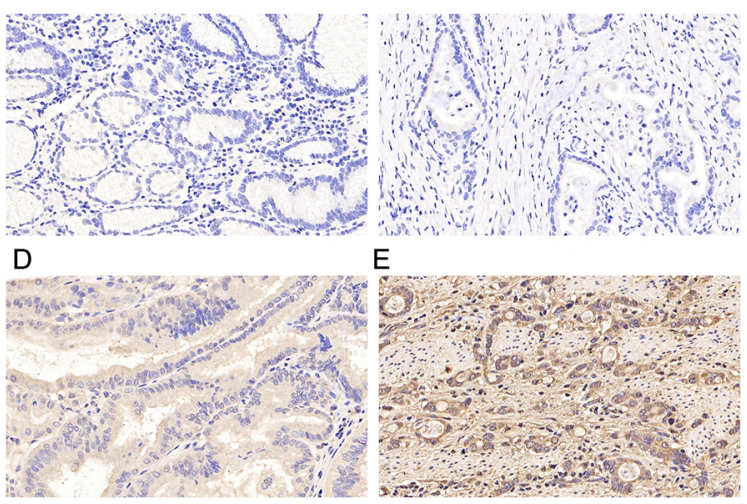

G

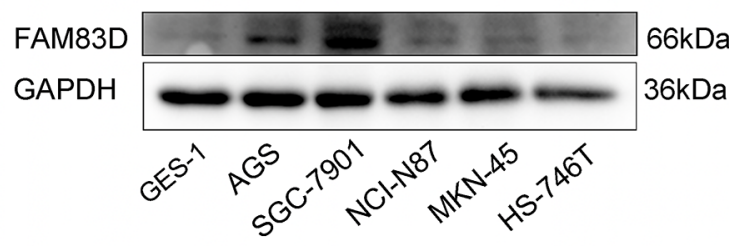

$\mathrm{F}$

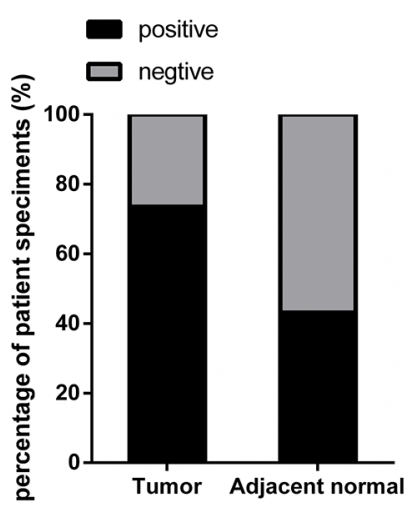

$\mathrm{H}$

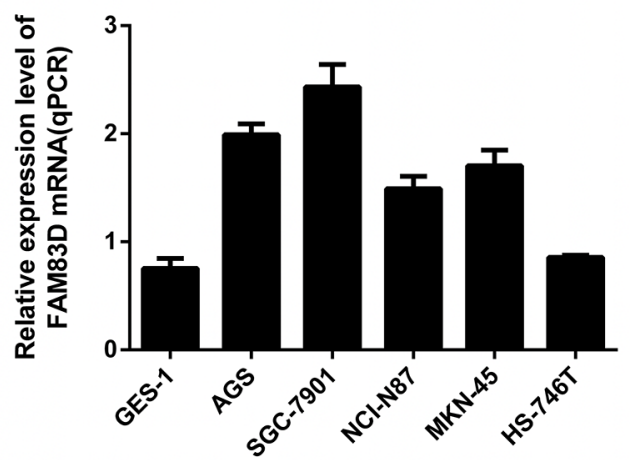

Figure 1: Expression of FAM83D in human gastric tumor tissues and cell lines. (A) Immunofluorescence images of AGS cells at interphase and metaphase stained with antibodies against FAM83D (red), $\alpha$-tubulin (green), and DAPI (blue). (B) Negative FAM83D expression in the non-tumor gastric mucosa (200x). (C, D, and E) Negative, weak positive and strong positive FAM83D expression in gastric cancer tissues. (F) Positive ratios of FAM83D expression in 102 pairs of gastric cancer tissues. (G and $\mathbf{H}) \mathrm{mRNA}$ and protein expression of FAM83D in GC cell lines. 
Table 1: Correlation of FAM83D expression with clinic-pathologic features

\begin{tabular}{|c|c|c|c|c|}
\hline \multirow[t]{2}{*}{ Variables } & \multirow[t]{2}{*}{ Number of cases } & \multicolumn{2}{|c|}{ FAM83D immunostaining } & \multirow[t]{2}{*}{ P value } \\
\hline & & Positive & Negative & \\
\hline \multicolumn{5}{|l|}{ Gender } \\
\hline male & 72 & 50 & 22 & 0.105 \\
\hline female & 30 & 25 & 5 & \\
\hline \multicolumn{5}{|l|}{ Ags(years) } \\
\hline$<60$ & 44 & 35 & 9 & 0.235 \\
\hline$\geq 60$ & 58 & 40 & 18 & \\
\hline \multicolumn{5}{|l|}{ Differentiation } \\
\hline well to moderate & 37 & 28 & 9 & 0.675 \\
\hline poor & 65 & 47 & 18 & \\
\hline \multicolumn{5}{|l|}{ Poortumor size } \\
\hline$\leq 5$ & 60 & 46 & 14 & 0.447 \\
\hline$>5$ & 42 & 29 & 13 & \\
\hline \multicolumn{5}{|l|}{ T stage } \\
\hline $\mathrm{T} 1+\mathrm{T} 2$ & 17 & 9 & 8 & 0.067 \\
\hline $\mathrm{T} 3+\mathrm{T} 4$ & 85 & 66 & 19 & \\
\hline \multicolumn{5}{|c|}{ Lymph node metastasis } \\
\hline YES & 71 & 58 & 13 & 0.006 \\
\hline NO & 31 & 17 & 14 & \\
\hline \multicolumn{5}{|l|}{ TNM stage } \\
\hline $\mathrm{I}+\mathrm{II}$ & 38 & 20 & 18 & $<0.001$ \\
\hline $\mathrm{III}+\mathrm{IV}$ & 64 & 55 & 9 & \\
\hline
\end{tabular}

this kinase appears to stimulate timely mitotic entry through the activation of PLK1 and the Cyclin-B1/Cdk1 complexes [30, 31]. Collectively, these observations raise a strong possibility that FAM83D coordinates cell cycle progression in human cancer cells by binding with HMMR, TPX2, and AURKA.

Based on emerging molecular and functional links of FAM $83 D$ to mitosis, we hypothesized that FAM $83 D$ promotes gastric tumor growth and progression by stimulating cell cycle progression through binding with HMMR, TPX2, and AUKRA. To test this hypothesis, we analyzed effects of FAM $83 D$ overexpression and knockdown on cancer cell cycle progression, tumor growth, and metastasis. Also, immunoprecipitation was carried out to evaluate the interaction between FAM83D and HMMR, TPX2 and AUKRA. In addition, IHC analyses of human tumor tissues were conducted to determine the correlation between FAM $83 D$ and key clinical characteristics of GC. Data from our analyses demonstrate that FAM $83 D$ promotes tumor growth and metastasis in gastric cancer. To a larger extent, these functions of FAM $83 D$ are linked to the control of cell cycle progression and correlated with MAPs. As such, our study has provided strong evidence that FAM $83 D$ is a key driver of tumor development and progression in gastric cancer and is a promising therapeutic target for the treatment of this disease.

\section{RESULTS}

\section{Association between $F A M 83 D$ expression and key clinicopathological parameters of human gastric cancer}

To evaluate FAM $83 D$ expression pattern in human GC, immunohistochemistry (IHC) was performed in 102 tumor samples and matched non-tumor tissue pairs. Our data showed that $73.5 \%$ ( 75 of 102 positive) tumor samples showed positive staining for FAM83D, whereas in non-tumor tissue samples, 44 out of 102 stained positive $(\mathrm{P}<0.01)$ (Figure 1B-1F). Furthermore, high FAM83D upregulation was strongly correlated with 
an increased lymph node metastasis, advanced TNM stage $(\mathrm{P}=0.006 ; \mathrm{P}<0.001)$, but not with other clinical parameters (Table 1). In parallel, our analyses of the published Gene Expression Omnibus (GEO) database $[32,33]$ showed that FAM $83 D$ was also significantly higher at mRNA level in gastric cancer group than their normal counterparts $(\mathrm{P}=4.60 \mathrm{E}-05, \mathrm{P}=0.000217)$. Moreover, a similar trend was detected for FAM83D in our analyses with human GC cell lines, including AGS, SGC-7901, NCI-87, MKN-45, HS-746T and one immortalized normal gastric epithelial cell line (GES1) (Figure 1G-1H). Together, these data demonstrate an upregulation of $F A M 83 D$ expression in human gastric tumors and implicate its role in the development of GC.

\section{FAM83D drives GC cell proliferation}

Based on the clinical link, we evaluated the function of FAM83D in human GC. As shown in Figure 2A-2B, overexpressing FAM 83 D markedly increased cell proliferation in both 746T and AGS lines, compared to each of their vector controls. Conversely, knockdown of FAM83D via three distinct RNAi oligos (Supplementary Table 1, Supplementary Figure 1B) led to a decrease in cell growth (Figure 2C-2D, Supplementary Figure 2A). In addition, a similar trend was detected for colony formation by GC cells upon overexpression or knockdown of FAM 83 D (Figure 2E-2G, Supplementary Figure $2 \mathrm{~B}, \mathrm{P}<0.01)$. Together, these data demonstrated that FAM 83 D promoted cell proliferation of GC cells.
A

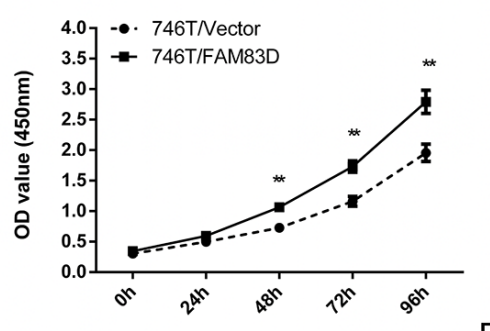

C

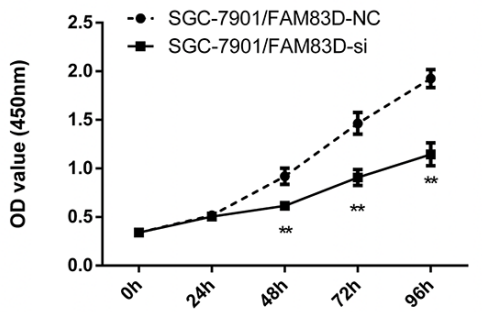

$E$

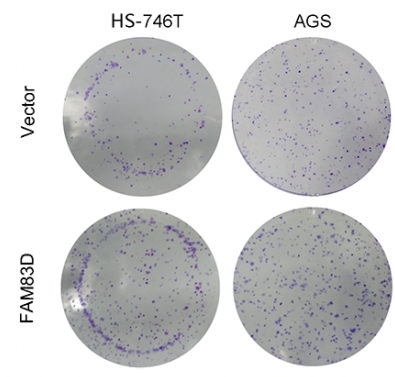

$\mathrm{F}$

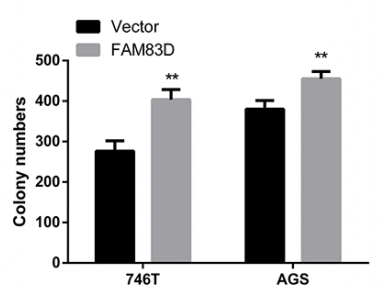

B

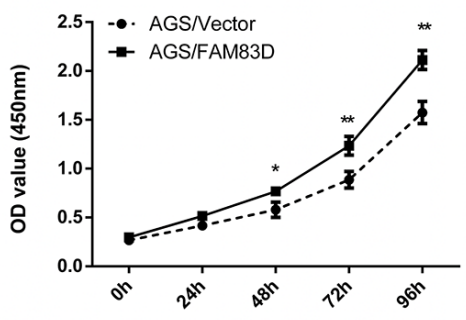

D
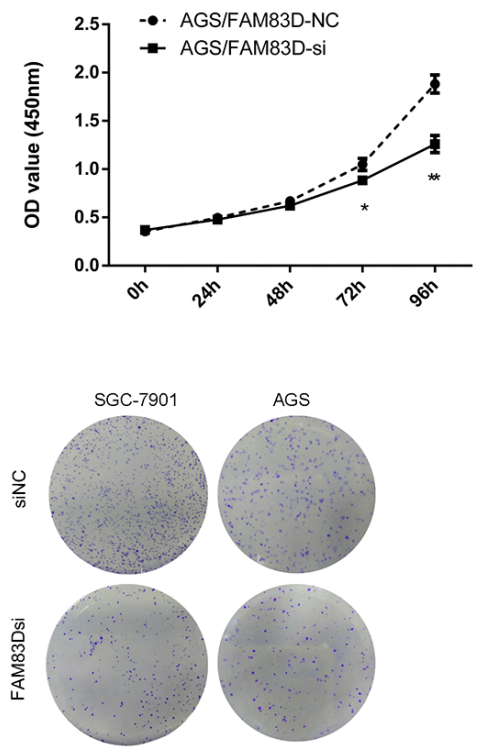

G

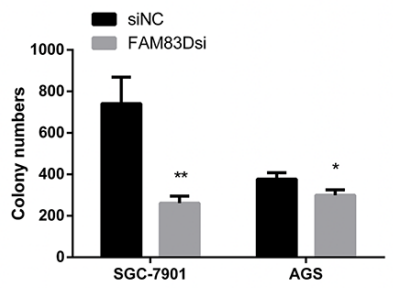

Figure 2: Ectopic expression of FAM83D promotes GC cell proliferation. (A and B) The effect of FAM83D overexpression on HS-746T and AGS cells proliferation were measured by Cell Counting Kit-8 assay. (C and D) SGC-7901 and AGS cells transfected with FAM83D siRNA and controls at 24 h post-transfection were subjected to CCK8 assay. (E, F, and G) Photographs and histograms of colony formation assay demonstrated the number of colonies, ${ }^{*} \mathrm{P}<0.05, * * \mathrm{P}<0.01$. 
We next tested if FAM83D promoted cell proliferation by impacting cell-cycle progression. As shown in Figure 3 and Supplementary Figure 2C, FAM83D siRNA-treated AGS and SGC-7901 cells led to a significant increase in the proportion of tumor cells at the G2-M phase (AGS: $23.26 \% \pm 2.65 \%$ vs. $17.42 \%$ $\pm 2.36 \%, \mathrm{P}<0.05$; SGC-7901: $27.67 \% \pm 3.96 \%$ vs. $19.68 \% \pm 1.86 \%, \mathrm{P}<0.05)$. Conversely, overexpressing

A
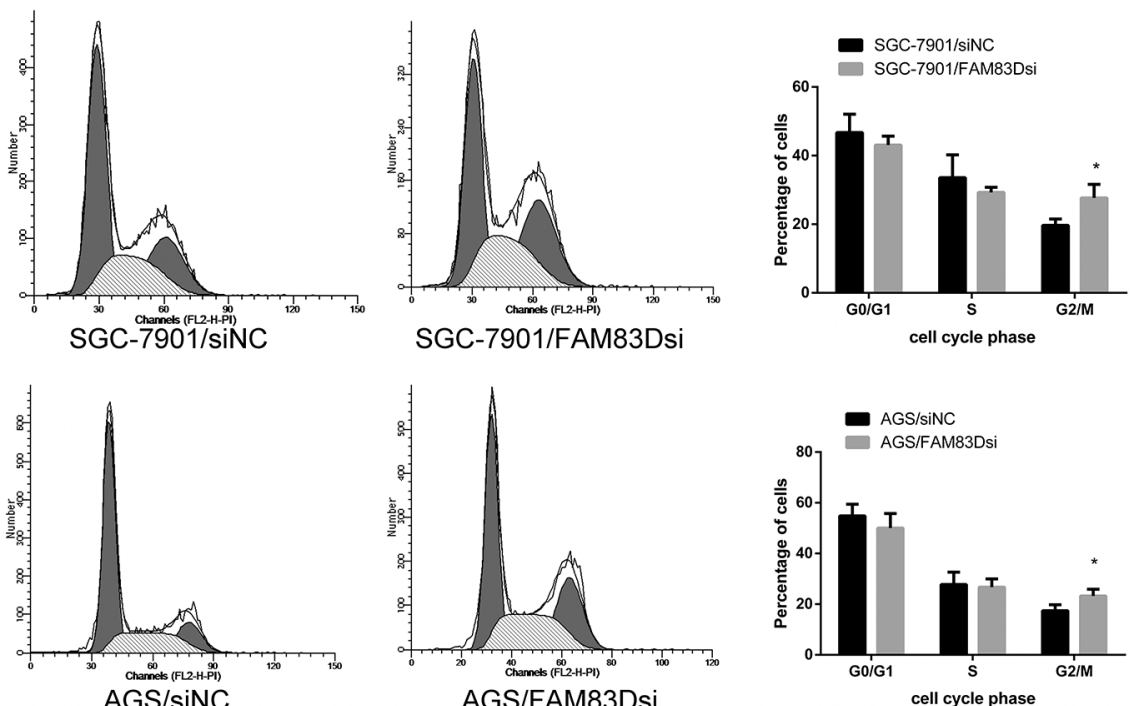

B

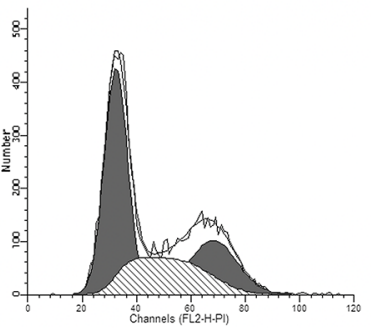

HS-746TNector

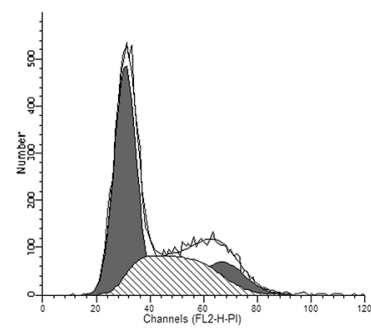

HS-746T/FAM83D
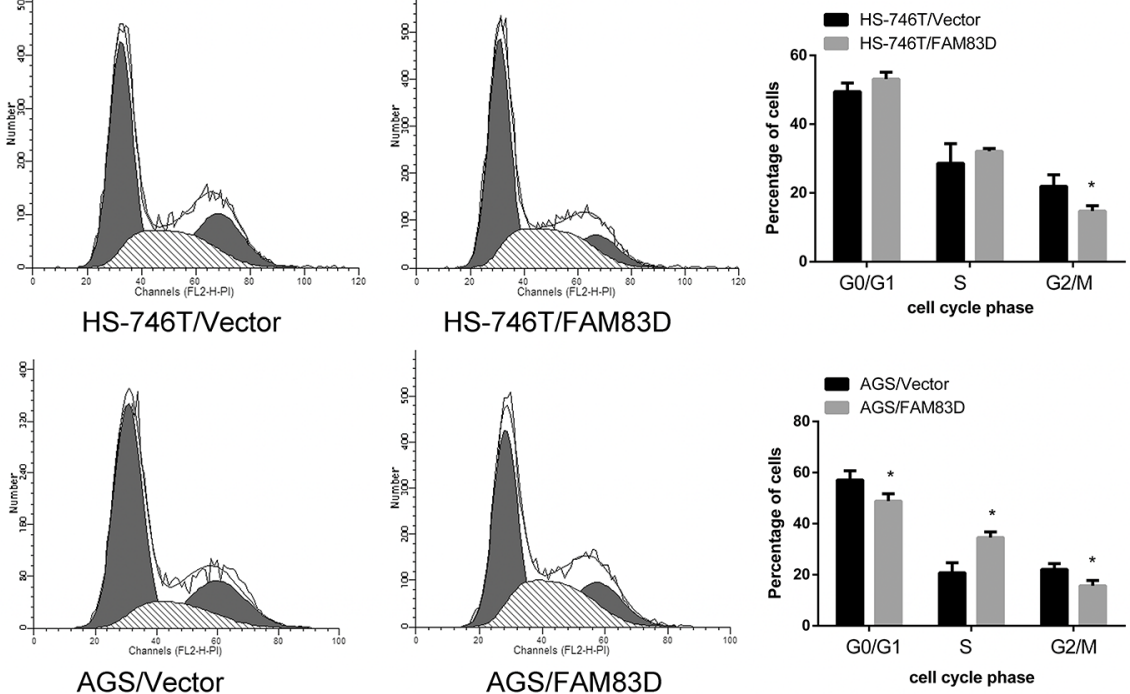

C

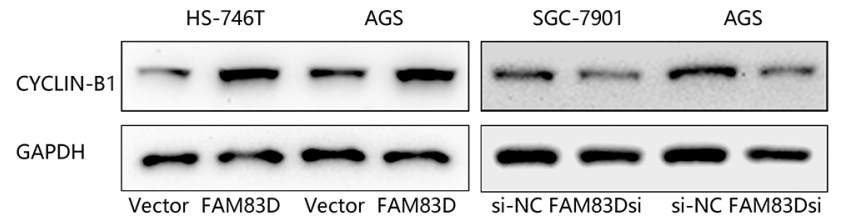

Figure 3: Effect of FAM83D on the cell cycle in GC cells. (A) Flow cytometry analysis was performed on SGC-7901 and AGS cells that were transfected with FAM83D siRNA and control siRNA. (B) Flow cytometry analysis was performed on FAM83D-expressing HS-746T and AGS cells. (C) Western blot analysis of cyclin-B1. 
FAM83D decreased the proportion of tumor cells in the G2/M phase. Notably, the proportions of cells at the G2/M phase for $F A M 83 D$-overexpression and control cells were $3.06 \% \pm 1.00 \%$ and $10.62 \% \pm 4.32 \%$, in AGS line, respectively $(\mathrm{P}<0.05)$, and $4.17 \% \pm 3.73 \%$ and $11.35 \%$ $\pm 1.81 \%$ in HS-746T cell line $(\mathrm{P}<0.05)$. Interestingly, overexpressing FAM83D in AGS line also reduced the distribution of tumor cells in the $\mathrm{G} 1 / \mathrm{G} 0$ phase $(56.99 \%$ $\pm 2.27 \%$ vs. $66.50 \% \pm 5.36 \%, \mathrm{P}<0.05)$. Collectively, these observations suggested that FAM $83 D$ promotes proliferation of $\mathrm{GC}$ cells by accelerating cell cycle progression through both G1/S and G2/M phases.

To further clarify the nature of the G2/M delay associated with FAM 33 D deficiency, the protein level of cyclin-B1, a hallmark of G2/M phase [34], was examined. The knockdown of FAM83D level led to a striking decrease of the cyclin-B1 level. In contrast, the opposite results were obtained with FAM83D overexpression (Figure 3C). Taken together, FAM $83 D$ is crucial in the promotion or development of tumor cell growth while ablation of FAM $83 D$ negative impacts proliferate capacity. The effect of FAM83D knockdown on cell apoptosis and senescence was further investigated. We detected a minimal difference in the percentage of Annexin $\mathrm{V}$-positive apoptotic or $\beta$-Gal- positive senescent cells between the FAM $83 D$ knockdown and control groups (data not shown). Thus, FAM $83 D$ increases proliferation of GC cells by enhancing cell cycle progression, rather than the induction of cell apoptosis or senescence.

\section{FAM83D promotes the wound healing, migration, and invasion of GC cells}

We also investigated if FAM $83 D$ contributed to the migration and invasion of GC cells. In wound healing assay, we observed that the wound healing area of AGS/FAM83D and HS-746T/FAM83D cells was markedly smaller than those of AGS/Vector or HS-746T/ Vector cells while migration of the AGS and SGC7901 cells was inhibited by FAM83D silencing (Figure 4A, Supplementary Figure 2D). To determine whether ectopic expression of FAM $83 D$ altered cell migration and invasion, Transwell assays were performed. Knockdown of FAM $83 D$ attenuated migration (AGS/FAM83Dsi vs. AGS/si-NC: $94.00 \pm 14.42$ vs. $296.67 \pm 15.28$ cells per field, $\mathrm{P}<0.001$; SGC-7901/FAM83Dsi vs. SGC-7901/ si-NC: $100.00 \pm 10.00$ vs. $254.00 \pm 14.00$ cells per field, $\mathrm{P}<0.001)$ and invasion $(\mathrm{AGS} / F A M 83 D \mathrm{si}$ vs. AGS/siNC: $36.33 \pm 10.07$ vs. $100.33 \pm 20.50$ cells per field, $\mathrm{P}$ $<0.01$; SGC-7901/FAM83Dsi vs. SGC-7901/ si-NC: $57.00 \pm 8.54$ vs. $96.67 \pm 16.07$ cells per field, $\mathrm{P}<0.05$ ). Consistent with these observations, overexpression of FAM 33 increased cell migration in both AGS and HS746T lines (AGS/FAM83D vs. AGS/Vector: $402.33 \pm$ 24.01 vs. $175.67 \pm 12.90$ cells per field, $\mathrm{P}<0.001$; HS$746 \mathrm{~T} / F A M 83 D$ vs. HS-746T/Vector: $485.00 \pm 31.48$ vs.
$225.67 \pm 24.11$ cells per field, $\mathrm{P}<0.001)$. Similarly, the numbers of invaded cells were nearly doubled in AGS or HS-746 line, when FAM $83 D$ was overexpressed (Figure 4B-4D, Supplementary Figure 2E). Next, protein level of $N$-cadherin, Vimentin increased in HS-746T/FAM $83 D$ cells indicating FAM $83 D$ overexpression promotes epithelialmesenchymal transition (EMT) in tumor progression (Supplementary Figure 1D). Together, these results demonstrate that the ectopic expression of FAM $83 D$ drives the motility and invasion of GC cells.

\section{Overexpressing FAM83D enhances tumor growth and peritoneal dissemination in vivo}

The xenograft analyses were conducted to evaluate the role of FAM $83 D$ in the tumorigenicity as well as metastatic progression through peritoneal dissemination in GC. Our data showed that tumor volume or weight in mice injected with the FAM $83 D$-overexpressing cells were significantly larger than the control group ( $\mathrm{P}$ $<0.006$ ) (Figure 5A-5C). Moreover, the Ki-67 staining was significantly higher in the HS-746T/FAM83D tumors (Figure 5D). Likewise, in peritoneal metastasis mouse models, there were significantly more visible peritoneal nodules in the HS-746T/FAM83D group compared with controls $(\mathrm{P}=0.029)$ (Figure 5F-5G). In addition, 2 out of 5 mice injected with the HS-746T/FAM83D cells developed larger tumors in the liver, but not in the control group $(0 / 5)$ (Figure 5E). Together, these results illustrate a strong promoting role of FAM $83 D$ in gastric tumor growth metastasis in vivo.

\section{FAM83D knockdown impairs microtubule regrowth}

Cell division requires maintenance of a highly ordered bipolar structure. Thus, a subtle change in nonmotor proteins may lead to genetic alteration, which in turns causes cancer or other human diseases. Despite being localized mainly to non-kinetochore microtubules, the FAM $83 D$ depletion appears to have no effect on $\mathrm{K}$ fiber stability $[13,15]$. In line with this conclusion, we explored whether cold-sensitive microtubules regrowth was impaired in FAM $83 D$-depleted cells. After transfected with siRNA for $36 \mathrm{~h}$, cells were treated on ice $\left(4{ }^{\circ} \mathrm{C}\right)$ for 40 minutes to fully depolymerize non-kinetochore microtubules, and then transferred to $37^{\circ} \mathrm{C}$ for 3 or 10 minutes to allow microtubule regrowth. The intriguing finding demonstrated that microtubule nucleation from centrosomes was not affected as astral microtubules were normally formed from centrosomes after $3 \mathrm{~min}$ at $37^{\circ} \mathrm{C}$. However, spindles in AGS/FAM83Dsi cells were frequently abnormal and disorganized after 10 minutes at $37{ }^{\circ} \mathrm{C}$, being mono-polar, multi-polar or collapsed in $11.1 \%, 16.7 \%$ and $2.7 \%$ of cases, respectively (Figure 6A-6B). All these data pointed out that lack of FAM $83 D$ 
resulted in aberrant spindle formation and maintenance during mitosis. However, referring to cancer issues, ectopic expression of FAM83D contributes to tumor progression.

\section{FAM83D expression is cell cycle dependent}

The level of FAM83D amplification during mitosis has been reported in Hela S3 cells, suggesting a role in mitosis [13]. In order to confirm and further investigate the protein expression pattern of cell cycle progression, we examined cell cycle phase distribution of the cells synchronized with double-thymidine block (Figure 6C6D). As a reference, population doubling time in ATCC (American Type Culture Collection) website is $20 \mathrm{hrs}$. At various time points after release, cells were harvested, and FAM $83 D$ protein level was analyzed by Western blot. In parallel, cell cycle distribution was analyzed via
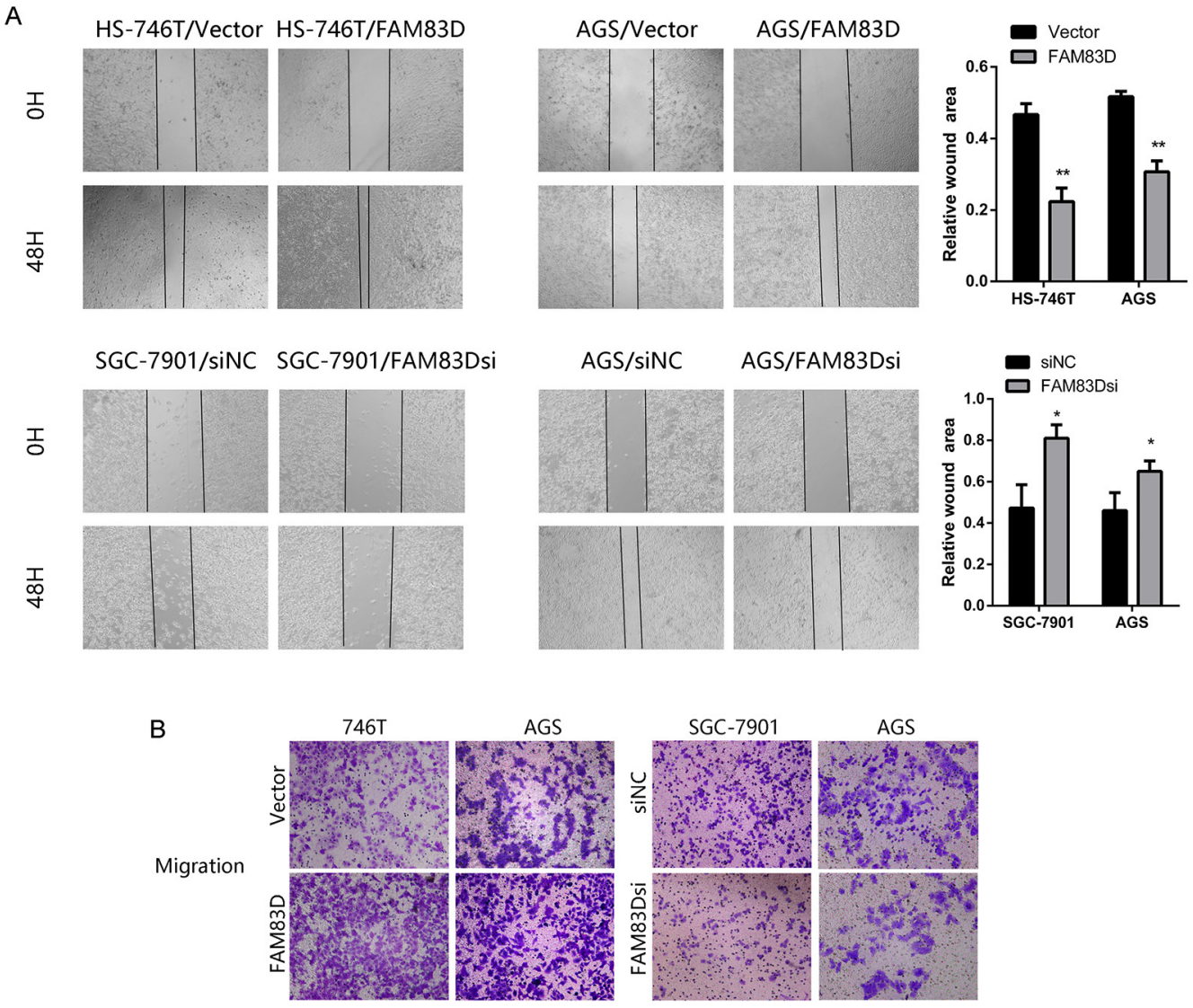

C
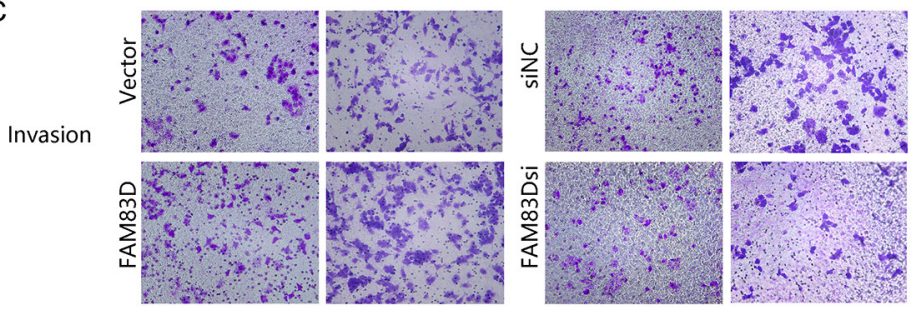

D
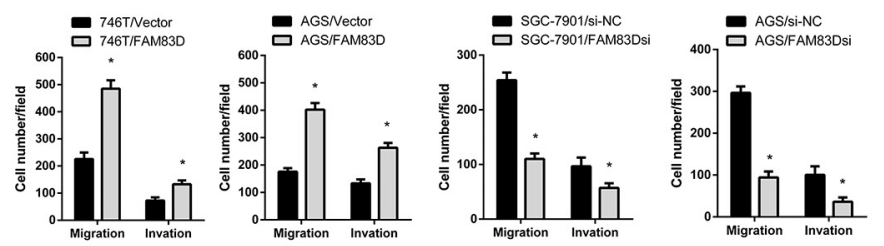

Figure 4: FAM83D enhances migration and invasion of GC cells. (A) Wound healing assay. Microscopic observations were recorded 0 and 48 hours after scratching the cell surface. (B and C) Transwell assay (100x). Representative photographs of migrating or invaded cells on membranes with or without Matrigel are shown. (D) Histograms showed the numbers of migration cells and invasion cells. Cells were counted in five randomly selected microscopic fields. Data are means $\pm \mathrm{SD}$ of three independent experiments, $* \mathrm{P}<0.05$. 
flow cytometry by monitoring the DNA content. The data showed that the FAM83D protein level was cell cycle correlated, which started to rise in the S phase and peaked in the G2/M phase (Figure 6E-6F). Since FAM83D is a microtubule-associated protein, we have confirmed its cellular localization at different cell cycle stages through fluorescence microscope (Supplementary Figure 1A), which was in corresponding with previous researches $[13,15]$.
A

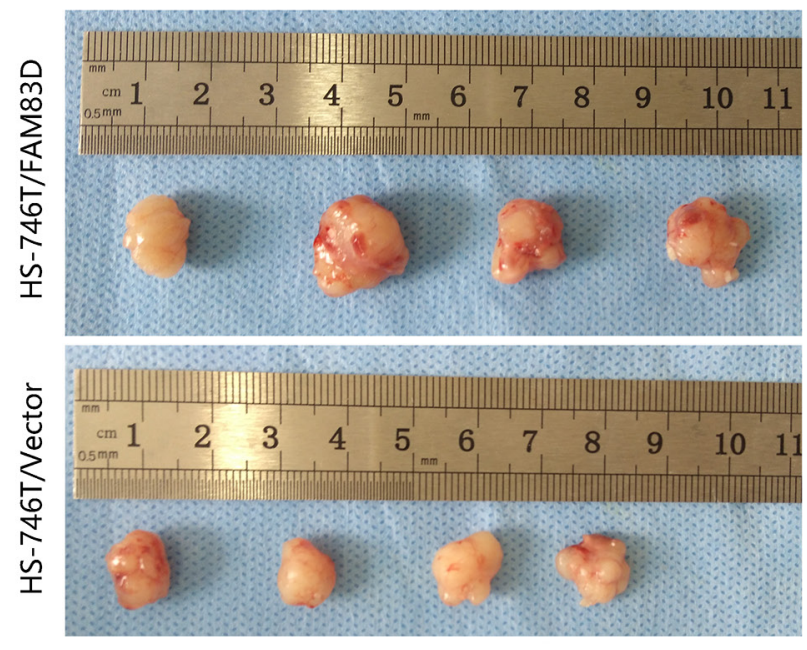

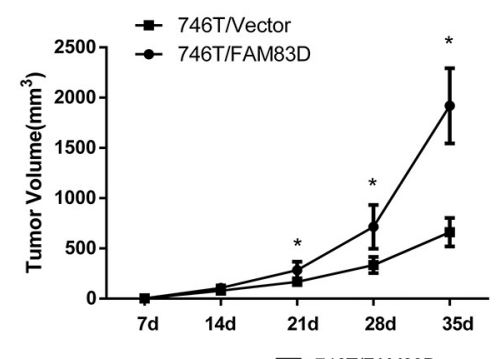

C

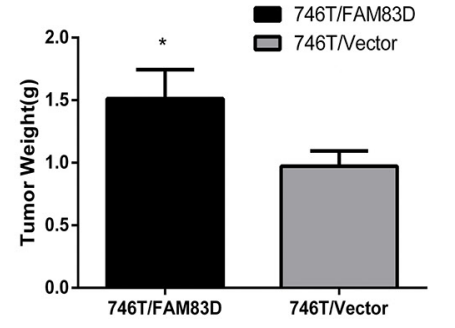

D

HS-746T/FAM83D HS-746T/Nector

E
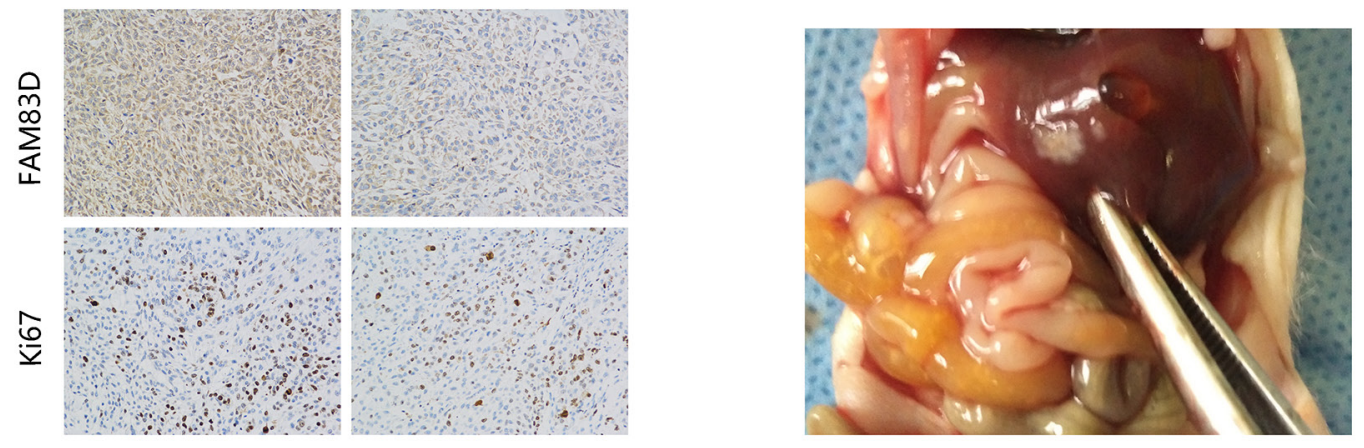

F

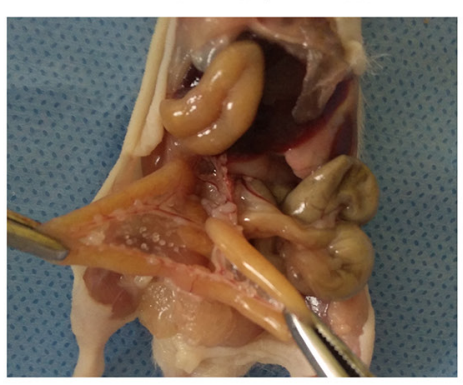

HS-746T/Vector

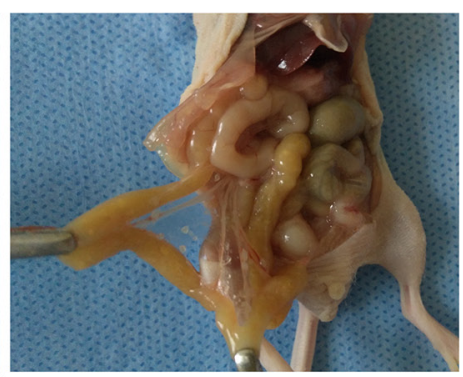

G

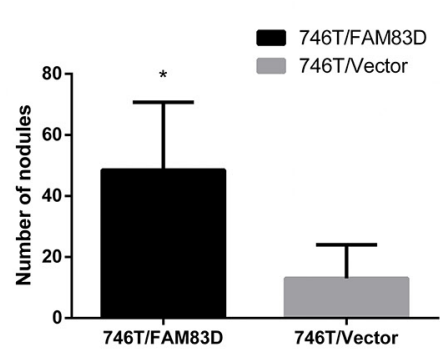

Figure 5: Overexpression of FAM83D promotes subcutaneous tumor growth and peritoneal and other metastases in nude mice. (A) Photographs of tumors in nude mice derived from HS-746T/FAM83D and HS-746T/Vector cells. (B) Growth kinetics of tumors in nude mice. Tumor diameters were measured every 7 days, $* \mathrm{P}<0.05$. (C) The average weight of tumors in nude mice, $* \mathrm{P}<$ 0.05. (D) Representative photographs of immunohistochemical analysis of FAM83D and Ki-67 antigen in tumors from HS-746T/FAM83D and controls (200x). (E) One representative visible nodule on the liver surface. (F) Photographs of the peritoneal nodules. (G) An average number of peritoneal nodules in each mouse, $* \mathrm{P}<0.05$. 
FAM83D physically binds to a subset of mitotic spindle proteins

The localization of FAM83D at the mitotic spindle raises a possibility that FAM83D may stimulate spindle formation and mitotic progression through protein interaction on the spindle. A recent research analyzing FAM $83 D$-coexpressed genes in various tumor types was performed using the Oncomine cancer microarray database, of which, 150 genes were strongly linked

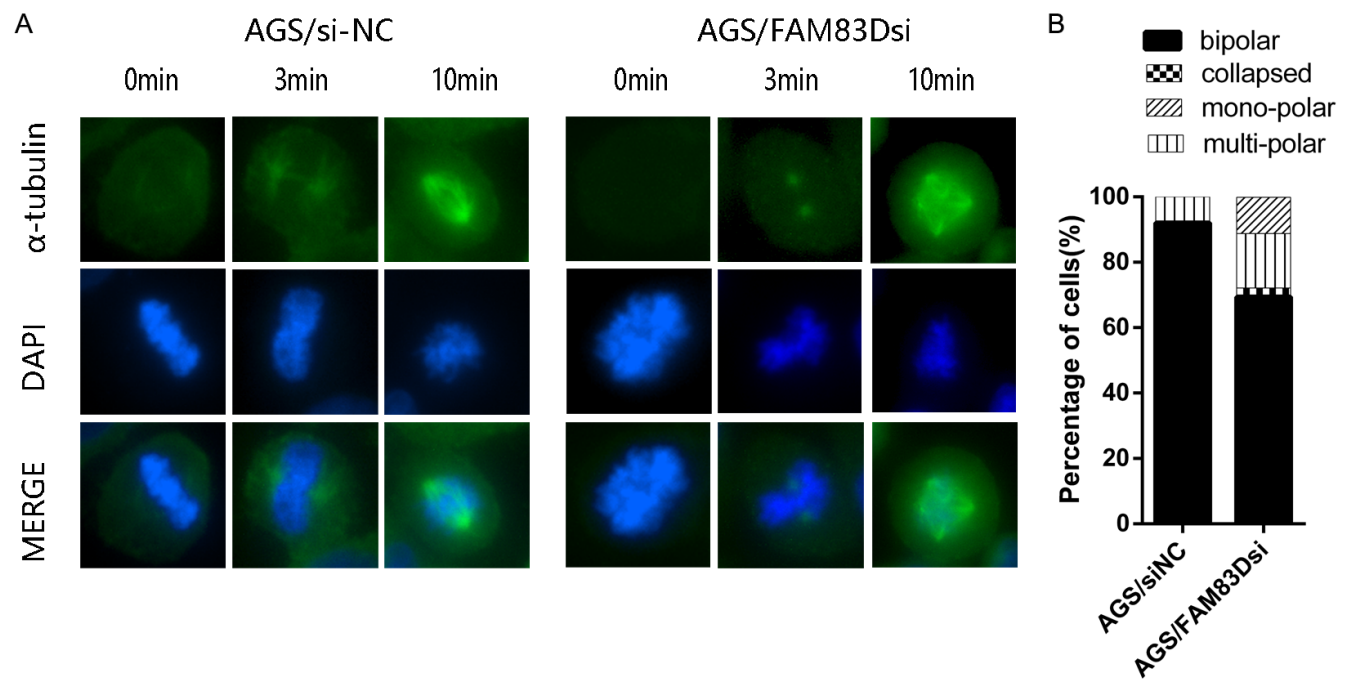

。

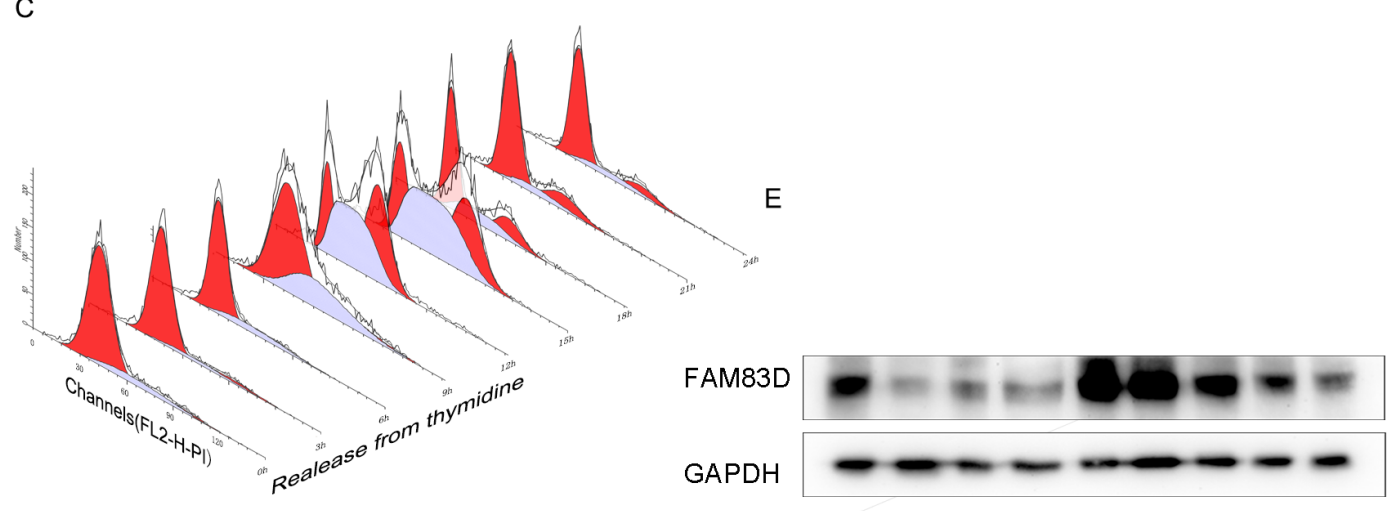

D

$\mathrm{F}$
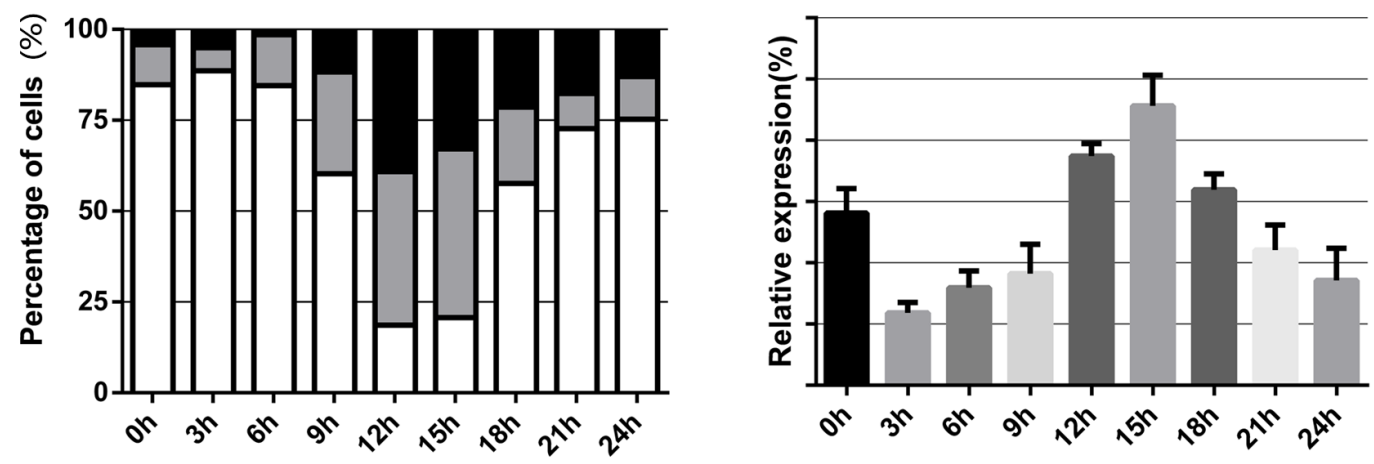

Figure 6: Cold-sensitive microtubules regrowth assay and cell cycle dependent FAM83D expression. (A) After AGS cells had been transfected with FAM83D siRNA and controls for $36 \mathrm{~h}$, cells were incubated at $37^{\circ} \mathrm{C}$ for 3 or 10 minutes after cold treatment to allow further spindle formation (200x). (B) Histograms showed the percentage of spindle abnormalities. (C and D) AGS cells were synchronized by double-thymidine block and released. The cell cycle progression was followed by flow-cytometry analysis. (E and F) The expression pattern of FAM83D in synchronized AGS cells was analyzed by Western blot. 
with cell cycle and mitosis based on pathway function enrichment, including AURKA, AURKB, CCNA2, CCNB1-2, CDC20, CDC25A-C, HMMR, PLK1, TPX2 [35]. Among which, HMMR was found to correlate FAM83D, TPX2 to the spindle, while TPX2 was required for targeting and activating AURKA [15, 19-21]. Based on the previous researches, we hypothesize that FAM83D could bind with HMMR, TPX2, AUKRA on spindle during mitosis and functioned as a complex. HMMR, $T P X 2$ and $A U R K A$ protein levels peaked in mitosis compared with the G0/G1 phase in AGS cells using nocodazole and thymidine block separately investigated by Western blot (Figure 7A). Our immunoprecipitation analyses showed that the Flag-tagged FAM83D was co-immunoprecipitated with endogenous FAM83D, $\alpha$-tubulin, HMMR, TPX2 and AURKA in AGS cells, and vice versa. (Figure $7 \mathrm{~B}$ ). These data demonstrate strong physical interactions between FAM83D and a set of spindle-linked proteins, including HMMR, TPX2, and AURKA, in human gastric tumor cells.

A

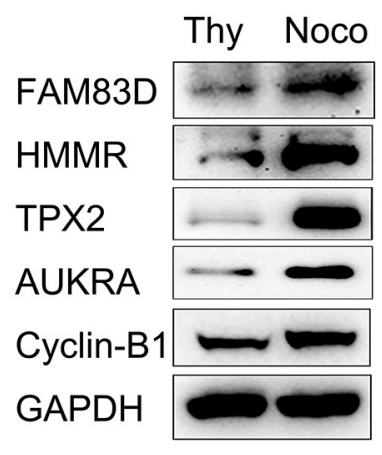

B

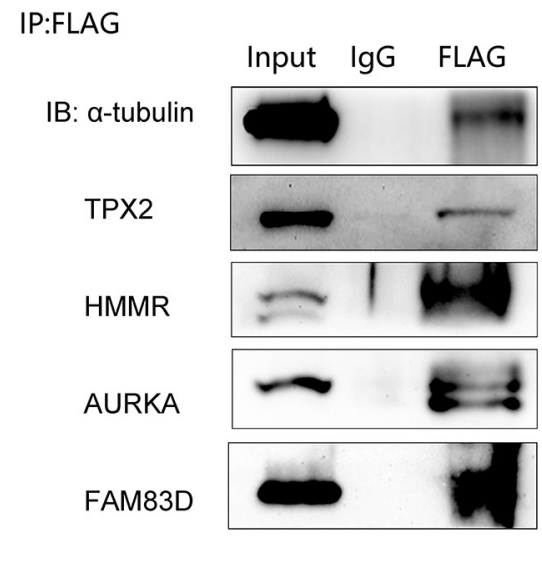

IP:TPX2

IB:TPX2

a-tubulin

HMMR

AURKA

FAM83D

$$
\text { Input IgG TPX2 }
$$
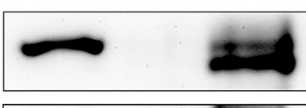

IP: HMMR

IB: HMMR

a-tubulin

TPX2

FAM83D

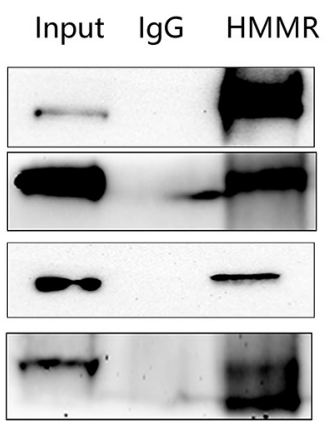

IP:a-tubulin

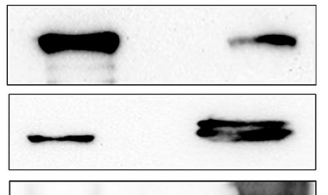

IB: $\boldsymbol{\alpha}$-tubulin

Input $\lg G \quad \alpha$-tubulin

HMMR

TPX2

FAM83D
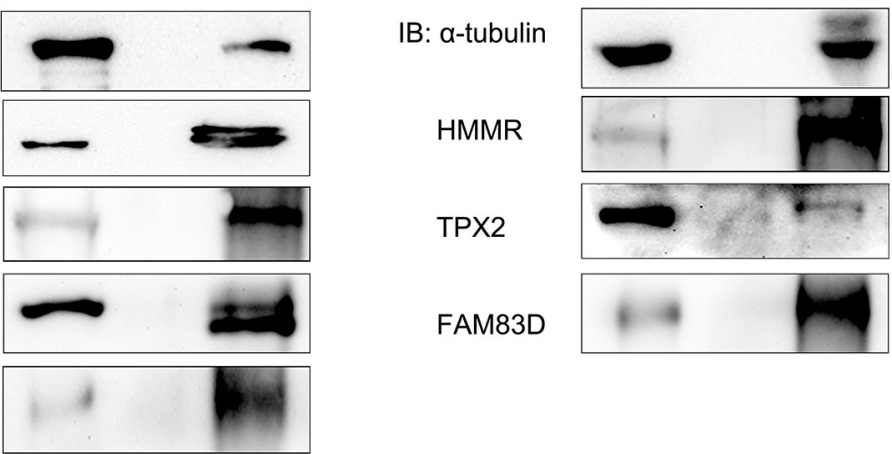

Figure 7: Physical interaction among FAM83D, $\boldsymbol{\alpha}$-tubulin, HMMR, TPX2 and AURKA. (A) FAM83D, HMMR, TPX2, and AURKA expression peaked in mitosis compared with G0/G1 phase analyzed by Western blot, with cyclin-B1 as the positive control. (B) FAM83D was physically associated with $\alpha$-tubulin, HMMR, TPX2 and AURKA via co-immunoprecipitation analysis in flag-tagged AGS/ FAM83D cells. 


\section{DISCUSSION}

Prior to the current study, there was little known about the function of FAM $83 D$ in GC. Here, we show that FAM $83 D$ is overexpressed in human gastric tumors, and its overexpression strongly correlates with lymph node metastasis and TNM stage. Our functional analyses also reveal that FAM $33 D$ overexpression promotes tumor cell proliferation, colony formation, migration, and invasion, as well as tumor growth and metastatic dissemination. Furthermore, we demonstrate that FAM $83 D$ drives cell cycle progression through the G2/M phase. This function may largely associate with the physical binding between FAM83D and a set of spindle-linked regulators, including HMMR, TPX2, and AURKA. Nevertheless, our study provides evidence for the first time that lack of FAM $83 D$ leads to aberrant spindle formation. Importantly, our data show that FAM $83 D$ is essential for maintaining normal MT related event, and confers strong oncogenic activity upon overexpression. Together, our study suggests that FAM $83 D$ is a crucial driver of gastric tumor growth and metastasis.

Importantly, some previous researches have emphasized an important role of FAM83D in mitosis progression through correlating with other MAPs [13, 15]. Many genes like HMMR, TPX2, and AURKA are microtubule-associated proteins participating in cell division event and tumorigenesis [20-22, 24-27, 29, 36-39]. CO-IP revealed the interaction among FAM83D and three other proteins. Therefore we propose that the association of which gives rise to a novel functional unit with oncogenic properties. Most of the interacting genes, including FAM $83 D$, TPX2, and AURKA, are all located on $20 \mathrm{q}$, which is frequently amplified across many cancer types [7-9]. Mitotic network components such as AURKA/B signaling, FOXM1/PLK1 signaling and E2F/ targets of C-MYC are evaluated in most GC subtypes including EBV, MSI, and CIN, indicating the potential role of mitotic genes in GC [40]. This may in part explain the mutual promotion between genomic instability and amplifications of mitotic genes and cell cycle mediators.

Although the detailed mechanism underlying the cooperative function among FAM83D and HMMR/TPX2/ AURKA was not clear at this time, it suggests a novel potential candidate therapeutic target complex. Further investigation will be conducted to explore whether the TPX2/AURKA location is FAM83D dependent, whether the other three proteins could affect the FAM83D location, expression, phosphorylation, and function. How FAM83D functions to activate this unit or serves as a scaffold remains to be studied. Furthermore, our study suggests that FAM83D could accelerates the G1/S transition which is also consistent with a recent study on this molecule [6]. However, our observation that FAM $83 D$ ablation has a minimal suppression on cell apoptosis is deviated from a prior study on breast cancer [10]. These discrepancies are likely attributed to the variation in cancer type or cell line.
Therefore, it cannot be ruled out that various pathways and mechanisms FAM83D involved in proliferation.

Recently, neoadjuvant intraperitoneal and systemic chemotherapy (NIPS) trials using intraperitoneal paclitaxel are conducted in Asia [41-44]. Paclitaxel induces dysfunctional microtubules in mitosis, which leads to cell death [45]. To explore MAPs such as FAM83D may help to improve treatment outcome. Our further investigation will focus on the effects of FAM83D knockdown on the cytotoxicity of paclitaxel and whether that FAM83D knockdown sensitizes cells to paclitaxel treatment.

Overall, our study has demonstrated that FAM $83 D$ overexpression drives gastric tumor cell proliferation, migration, invasion as well as tumor growth and metastatic dissemination to peritoneal cavities in vivo. Also, FAM83D is essential for cell cycle progression. Given the notion that a subtle change in mitotic regulators at protein level could give rise to a great risk of cancer, our study underscores the potential of FAM $83 D$ as a valuable target for gastric cancer therapy.

\section{MATERIALS AND METHODS}

\section{Cell lines and cell culture}

Human gastric cancer cell lines, including AGS, SGC-7901, NCI-87, MKN-45, HS-746T, and GES-1, were purchased from Shanghai Institutes for Biological Sciences, Chinese Academy of Sciences. Cells were cultured in RPMI-1640 medium containing 10\% fetal bovine serum (FBS) at $37^{\circ} \mathrm{C}$ in a humidified atmosphere with $5 \% \mathrm{CO}_{2}$.

\section{Transfection and analyses of mRNA expression}

HS-746T, AGS cells were infected with the LentiFLAG-FAM83D and control Lenti-Vector purchased from Asia-Vector Biotechnology (Shanghai) Co. LTD and selected with $5 \mu \mathrm{g} / \mathrm{ml}$ blasticidin for 7 days. The siRNAs of FAM 33 were purchased from Shanghai GenePharma Co. LTD. The SGC-7901 and AGS cells were transiently transfected with siRNAs using Lipofectamine 2000 transfection reagent (Invitrogen), according to the manufacturer's recommendations (Supplementary Figure 1B-1C). The sequences of siRNAs were listed in Supplementary Table 1. Unless specified, FAM 33 D siRNA duplex number 1 was used for the following transfection.

For qRT-PCR analysis, total RNA isolation were described previously [46]. The primers were listed in Supplementary Table 2.

\section{Analyses of cell proliferation, colony formation, cell cycle and immunofluorescence}

Cell Counting Kit- 8 assay was performed as described [46]. For colony formation assay, cells were seeded in 6-well 
plates at a density of 1000 cells per well. After 7 days, colonies were visualized by crystal violet staining.

Serum starvation was used to induce cell cycle synchronization roughly before cell cycle distribution was analyzed by flow cytometry as described [46]. For analyzing FAM 33 D expression in the cell cycle, AGS cells were synchronized at $\mathrm{G} 0 / \mathrm{G} 1$ by double-thymidine block. Briefly, cells were treated with $2 \mathrm{mM}$ thymidine (Sigma, USA) for $20 \mathrm{~h}$, followed by culturing in fresh media for 9 $\mathrm{h}$. After that, cells were treated again with thymidine for $16 \mathrm{~h}$ and were released from the block by washing in PBS (phosphate-buffered saline) and culturing in fresh media. Samples were taken after block at 0, 3, 6, 9, 12, 15, 18, 21 , and 24 hours for flow cytometry analysis and Western blot analysis.

For the immunofluorescence analyses, tumor cells were incubated in 8-well glass slides (Millipore, USA) with primary antibodies against FAM83D (Bioss, CHINA), alpha-Tubulin (Proteintech, USA), followed by incubation with Goat anti-mouse $\operatorname{IgG}(\mathrm{H}+\mathrm{L})$, FITC conjugate or Goat anti-rabbit IgG $(\mathrm{H}+\mathrm{L})$, TRITC conjugate (Proteintech, USA). DNA was stained with 406-diamidino-2-phenylindole.

\section{Wound healing, transwell migration and invasion assays}

Monolayers of cells were plated in 6-well plates and grown until confluent. Scratch wounds were made using sterile $200 \mu \mathrm{l}$ pipette tips with non-adherent cells and debris removed by PBS washing. The cell motility images were photographed at 0,48 hours. Cell migration and invasion assays were assessed using transwell chambers (Corning Costar, USA). Especially for the invasion assay, the upper chamber was pre-coated with Matrigel (BD Bioscience, USA) according to the manufacturer's protocols. $1 \times 10^{5}$ cells in serum-free medium were added into the upper chamber, and medium with $10 \%$ FBS was added to the lower chamber. After cultured for $24 \mathrm{~h}$, cells that migrated through the membrane pores to the lower surface of the membrane were fixed with methanol and stained with $0.1 \%$ crystal violet for $30 \mathrm{~min}$.

\section{Immunoprecipitation (IP) and Western blot}

Preparation of cell lysates and immunoblotting were conducted as described in a prior study [46]. The primary antibodies used in the current study included those being anti-GAPDH (Proteintech, USA;1:10000), anti-Cyclin-B1 (Cell Signaling Technology (CST), USA;1:1000), antiFAM83D (Santa Cruz Biotechnology, USA;1:500), antiTPX2 (Abcam, USA;1:1000), anti-HMMR (Genetex, USA;1:1000), anti-AURKA (Abcam, USA;1:1000) and anti-FLAG (Proteintech, USA;1:5000).

For immunoprecipitation experiments, mitotic cells were incubated with $300 \mathrm{nM}$ nocodazole (Sigma, USA) for
$24 \mathrm{~h}$ and collected by shake-off. The cells were then lysed with NP-40 lysis buffer (Beyotime, CHINA)NP-40 Lysis BufferNP-40 Lysis BufferNP-40 Lysis Buffer and precleared for $30 \mathrm{~min}$ with protein $\mathrm{A} / \mathrm{G}$ plus agarose (Santa Cruz Biotechnology, USA). Pre-clear lysate, according to the manufacturer's instructions, were incubated with primary antibodies overnight at $4{ }^{\circ} \mathrm{C}$ on a rocker platform, followed by incubation with $20 \mu \mathrm{l}$ of re-suspended volume of protein $\mathrm{A} / \mathrm{G}$ plus agarose for $4 \mathrm{~h}$ at $4{ }^{\circ} \mathrm{C}$ with rotation. Washing was performed five times in $1.0 \mathrm{ml}$ lysis buffer, $5 \mathrm{~min}$ each on a rotator. Bound proteins were released by boiling in $20 \mu \mathrm{l}$ of Laemmli buffer.

\section{Immunohistochemistry (IHC) analyses of human tumor tissue microarrays}

Human gastric tumor and adjacent noncancerous tissues were obtained from patients undergoing radical gastrectomy at Ruijin Hospital, Shanghai Jiao Tong University School of Medicine (Details in Table 1 ). None of these patients received radiotherapy or chemotherapy prior to the surgery. All tumor tissues were fixed and assembled into paraffin-embedded tissue microarrays. The TNM-stages of patients were determined by the UICC TNM classification. The protocol for the human tissues-related analyses was approved by the Ethics Committee of Shanghai Ruijin Hospital, and all patients were fully informed of the experimental procedures. The IHC staining of human tumor tissues was conducted by use of a rabbit polyclonal antibody against FAM83D (Bioss, CHINA; 1:400), followed staining with secondary antibodies and $\mathrm{DAB}$, according to the protocol given by the manufacture (Dako, USA). The IHC staining was scored as previously described [46].

\section{Evaluation of tumor growth and metastasis in xenograft models}

Four-week-old male BALB/C nude mice were purchased from the Institute of Zoology, Chinese Academy of Sciences of Shanghai and housed in a specific pathogenfree environment. All experiments were performed in accordance with the official recommendations of the Chinese animal community. Briefly, 7x $10^{5}$ cells in $100 \mu 1$ PBS were injected subcutaneously into the dorsal flank of 8 nude mice or $2 \times 10^{5}$ cells in $200 \mu \mathrm{l}$ PBS injected into abdominal cavity of 10 mice. All mice were sacrificed after 40 days. Subcutaneous tumor grafts were weighted, and the quantity of nodules present in the abdominal cavity was measured.

\section{Statistical analyses}

All values in the text and figures were presented as mean \pm standard deviation (SD). Statistical analyses were performed using Student's t-test, $\chi^{2}$ test 
(GraphPad Prism 6). A two-tailed t-test at p-value $<0.05$ was considered statistically significant.

\section{Abbreviations}

FAM $83 D$, family with sequence similarity 83 , member D; MAP, microtubule-associated protein; $\mathrm{GC}$, gastric cancer; MT, microtubule; CO-IP, coimmunoprecipitation; HMMR, hyaluronan-mediated motility receptor; AURKA, aurora kinase A.

\section{ACKNOWLEDGMENTS}

Thanks to Dr. Xiuwei Yang from the University of Kentucky for critical reading of the manuscript.

\section{CONFLICTS OF INTERESTS}

None declared.

\section{FUNDING}

The project was supported by the Shanghai Municipal Education Commission (No. 13YZ025).

\section{REFERENCES}

1. Van Cutsem E, Sagaert X, Topal B, Haustermans K, Prenen H. Gastric cancer. Lancet. 2016; 6736: 1-11. https://doi. org/10.1016/S0140-6736(16)30354-3.

2. Bertuccio P, Chatenoud L, Levi F, Praud D, Ferlay J, Negri E, Malvezzi M, La Vecchia C. Recent patterns in gastric cancer : a global overview. Int J Cancer. 2009; 673: 666-73. https://doi.org/10.1002/ijc.24290.

3. Herrero R, Park JY, Forman D. The fight against gastric cancer - The IARC Working Group report. Best Pract Res Clin Gastroenterol. 2014; 28: 1107-14. https://doi. org/10.1016/j.bpg.2014.10.003.

4. Sauer G, Ko R, Hanisch A, Ries A, Nigg EA, Sillje HH. Proteome analysis of the human mitotic spindle. Mol Cell Proteomics. 2005; 4: 35-43. https://doi.org/10.1074/mcp. M400158-MCP200.

5. Cipriano R, Miskimen KL, Bryson BL, Foy CR, Bartel CA, Jackson MW. Conserved oncogenic behavior of the FAM83 family regulates MAPK signaling in human cancer. Mol Cancer Res. 2014; 12: 1156-65. https://doi. org/10.1158/1541-7786.MCR-13-0289.

6. Wang D, Han S, Peng R, Wang X, Yang X, Yang R, Jiao C, Ding D, Ji G, Li X. FAM83D activates the MEK / ERK signaling pathway and promotes cell proliferation in hepatocellular carcinoma. Biochem Biophys Res Commun. 2015; 458: 313-20. https://doi.org/10.1016/j. bbrc.2015.01.108.
7. Weiss MM, Snijders AM, Kuipers EJ, Ylstra B, Pinkel D, Meuwissen SG, van Diest PJ, Albertson DG, Meijer GA. Determination of amplicon boundaries at 20q13.2 in tissue samples of human gastric adenocarcinomas by highresolution microarray comparative genomic hybridization. J Pathol. 2003; 200: 320-6. https://doi.org/10.1002/ path.1359.

8. Sillars-Hardebol AH, Carvalho B, Tijssen M, Belien JA, de Wit M, Delis-van Diemen PM, Ponten F, van de Wiel MA, Fijneman RJ, Meijer GA. TPX2 and AURKA promote $20 \mathrm{q}$ amplicon-driven colorectal adenoma to carcinoma progression. Gut. 2012; 61: 1568-75. https://doi. org/10.1136/gutjnl-2011-301153.

9. Mantripragada K, Caley M, Stephens P, Jones C, Kluwe L, Guha A, Mautner V, Upadhyaya M. Identification of copy number gain and overexpressed genes on chromosome arm $20 q$ by an integrative genomic approach in cervical cancer: potential role in progression luigi. Genes Chromosomes Cancer. 2008; 47: 238-46. https://doi. org/10.1002/gcc.

10. Wang Z, Liu Y, Zhang P, Zhang W, Wang W. FAM83D promotes cell proliferation and downregulating tumor suppressor gene FBXW7. Oncotarget. 2013; 4: 2476-86. https://doi.org/10.18632/oncotarget.1581.

11. Liao W, Liu W, Liu X, Yuan Q, Ou Y, Qi Y. Upregulation of FAM83D affects the proliferation and invasion of hepatocellular carcinoma. Oncotarget. 2015; 6: 24132-47. https://doi.org/10.18632/oncotarget.4432.

12. Walian PJ, Hang B, Mao J. Prognostic significance of FAM83D gene expression across human cancer types. Oncotarget. 2016; 7: 3332-40. https://doi.org/10.18632/ oncotarget.6620.

13. Santamaria A, Nagel S, Sillje HH, Nigg EA. The spindle protein CHICA mediates localization of the chromokinesin kid to the mitotic spindle. Curr Biol. 2008; 18: 723-9. https://doi.org/10.1016/j.cub.2008.04.041.

14. Nousiainen M, Silljé HH, Sauer G, Nigg EA, Körner R. Phosphoproteome analysis of the human mitotic spindle. Proc Natl Acad Sci U S A. 2006; 103: 5391-6. https://doi. org/10.1073/pnas.0507066103.

15. Dunsch AK, Hammond D, Lloyd J, Schermelleh L, Gruneberg U, Barr FA. Dynein light chain 1 and a spindleassociated adaptor promote dynein asymmetry and spindle orientation. J Cell Biol. 2012; 198: 1039-54. https://doi. org/10.1083/jcb.201202112.

16. He J, Wu J, Xu N, Xie W, Li M, Li J, Jiang Y, Yang BB, Zhang Y. MiR-210 disturbs mitotic progression through regulating a group of mitosis-related genes. Nucleic Acids Res. 2013; 41: 498-508. https://doi.org/10.1093/nar/ gks995.

17. Parikh N, Hilsenbeck S, Creighton CJ, Dayaram T, Shuck R, Shinbrot E, Xi L, Gibbs RA, Wheeler DA, Donehower LA. Effects of TP53 mutational status on gene expression 
patterns across 10 human cancer types. J Pathol. 2014; 232: 522-33. https://doi.org/10.1002/path.4321.

18. Telmer PG, Tolg C, McCarthy JB, Turley EA. How does a protein with dual mitotic spindle and extracellular matrix receptor functions affect tumor susceptibility and progression? Commun Integr Biol. 2011; 4: 182-5. https:// doi.org/10.4161/cib.4.2.14270.

19. Maxwell CA, Keats JJ, Crainie M, Sun X, Yen T, Shibuya E, Hendzel M, Chan G, Pilarski LM. RHAMM is a centrosomal protein that interacts with dynein and maintains spindle pole stability. Mol Biol Cell. 2003; 14: 2262-76. https://doi.org/10.1091/mbc.E02.

20. Maxwell CA, Keats JJ, Belch AR, Pilarski LM, Reiman T. Receptor for hyaluronan-mediated motility correlates with centrosome abnormalities in multiple myeloma and maintains mitotic integrity. Cancer Res. 2005; 65: 850-60.

21. Kufer TA, Sillje HH, Korner R, Gruss OJ, Meraldi P, Nigg EA. Human TPX2 is required for targeting Aurora-A kinase to the spindle. J Cell Biol. 2002; 158: 617-23. https://doi. org/10.1083/jcb.200204155.

22. Chen H, Mohan P, Jiang J, Nemirovsky O, He D, Fleisch MC, Niederacher D, Pilarski LM, Lim CJ, Maxwell CA. Spatial regulation of Aurora A activity during mitotic spindle assembly requires RHAMM to correctly localize TPX2. 2014; 13: 2248-61.

23. Wittmann T, Wilm M, Karsenti E, Vernos I, Boleti H, Antony C, Karsenti E, Cell IV, Here B. TPX2, a novel xenopus MAP involved in spindle pole organization. J Cell Biol. 2000; 149: 1405-18.

24. Sohr S, Engeland K. RHAMM is differentially expressed in the cell cycle and downregulated by the tumor suppressor p53. Cell Cycle. 2008; 7: 3448-60. https://doi.org/10.4161/ cc. 7.21.7014

25. Reid TA, Schuster BM, Mann BJ, Balchand SK, Plooster M, McClellan M, Coombes CE, Wadsworth P, Gardner MK. Suppression of microtubule assembly kinetics by the mitotic protein TPX2. J Cell Sci. 2016; 129: 1319-28. https://doi. org/10.1242/jcs. 178806 .

26. Aguirre-Portolés C, Bird AW, Hyman A, Cañamero M, Pérez De Castro I, Malumbres M. Tpx2 controls spindle integrity, genome stability, and tumor development. Cancer Res. 2012; 72: 1518-28. https://doi.org/10.1158/0008-5472. CAN-11-197.

27. Asteriti IA, Rensen WM, Lindon C, Lavia P, Guarguaglini G. The Aurora-A/TPX2 complex: a novel oncogenic holoenzyme? Biochim Biophys Acta. 2010; 1806: 230-9. https://doi.org/10.1016/j.bbcan.2010.08.001.

28. Vader G, Lens SM. The Aurora kinase family in cell division and cancer. Biochim Biophys Acta. 2008; 1786: 60-72. https://doi.org/10.1016/j.bbcan.2008.07.003.

29. Yang G, Chang B, Yang F, Guo X, Cai KQ, Xiao XS, Wang H, Sen S, Hung M, Mills GB, Chang S, Multani S, Mercado-Uribe I, Liu J. Aurora kinase A promotes ovarian tumorigenesis through dysregulation of the cell cycle and suppression of BRCA2. Cancer. 2010; 16: 3171-81. https:// doi.org/10.1158/1078-0432.CCR-09-3171.Aurora.

30. Hirota T, Kunitoku N, Sasayama T, Marumoto T, Zhang D, Nitta M, Hatakeyama K, Saya H. Aurora-A and an interacting activator, the LIM protein Ajuba, are required for mitotic commitment in human cells. Cell. 2003; 114: 585-98. https://doi.org/10.1016/S0092-8674(03)00642-1.

31. Macůrek L, Lindqvist A, Lim D, Lampson MA, Klompmaker R, Freire R, Clouin C, Taylor SS, Yaffe MB, Medema RH. Polo-like kinase-1 is activated by aurora A to promote checkpoint recovery. Nature. 2008; 455: 119-23. https://doi.org/10.1038/nature07185.

32. Kimata YI, Kimata YI, Shimizu Y, Abe H, Farcasanu IC, Takeuchi M, Rose MD, Kohno K. Variation in gene expression patterns in human gastric cancers. Mol Biol Cell. 2003; 14: 2559-69. https://doi.org/10.1091/mbc.E02.

33. Errico MD, de Rinaldis E, Blasi MF, Viti V, Falchetti M, Calcagnile A, Sera F, Saieva C, Ottini L, Palli D, Palombo F, Giuliani A, Dogliotti E. Genome-wide expression profile of sporadic gastric cancers with microsatellite instability. Eur J Cancer. 2008; 45: 461-9. https://doi.org/10.1016/j. ejca.2008.10.032.

34. Nakayama Y, Yamaguchi N. Role of cyclin B1 levels in DNA damage and DNA damage-induced senescence. Int Rev Cell Mol Biol. 2013; 305: 303-37. https://doi. org/10.1016/B978-0-12-407695-2.00007-X.

35. Varisli L. Meta-analysis of the expression of the mitosisrelated gene Fam83D. Oncol Lett. 2012; 4: 1335-40. https://doi.org/10.3892/ol.2012.925.

36. Tolg C, Hamilton SR, Morningstar L, Zhang J, Zhang S, Esguerra KV, Telmer PG, Luyt LG, Harrison R, McCarthy JB, Turley EA. RHAMM promotes interphase microtubule instability and mitotic spindle integrity through MEK1/ ERK1/2 activity. J Biol Chem. 2016; 285: 26461-74. https://doi.org/10.1074/jbc.M110.121491.

37. Fu J, Bian M, Xin G, Deng Z, Luo J, Guo X, Chen H, Wang Y, Jiang Q, Zhang C. TPX2 phosphorylation maintains metaphase spindle length by regulating microtubule flux. J Cell Biol. 2015; 210: 373-83. https://doi.org/10.1083/ jcb.201412109.

38. Kufer TA, Nigg EA, Sillje HH. Regulation of Aurora-A kinase on the mitotic spindle. Chromosoma. 2003; 112: 159-63. https://doi.org/10.1007/s00412-003-0265-1.

39. Hsu PK, Chen HY, Yeh YC, Yen CC, Wu YC, Hsu CP, Hsu WH, Chou TY, Yeh PH. TPX2 expression is associated with cell proliferation and patient outcome in esophageal squamous cell carcinoma. J Gastroenterol. 2013; 49: 123140. https://doi.org/10.1007/s00535-013-0870-6.

40. Cancer Genome Atlas Research Network. Comprehensive molecular characterization of gastric adenocarcinoma. Nature. 2014; 513: 202-9. https://doi.org/10.1038/ nature 13480

41. Yonemura Y, Ishibashi H, Hirano M, Mizumoto A, Takeshita K, Noguchi K, Takao N, Ichinose M, Liu Y, Li Y. Effects 
of neoadjuvant laparoscopic hyperthermic intraperitoneal chemotherapy and neoadjuvant intraperitoneal/systemic chemotherapy on peritoneal metastases from gastric cancer. Ann Surg Oncol. 2017; 24: 478-85. https://doi.org/10.1245/ s10434-016-5487-6.

42. Yamaguchi H, Kitayama J, Ishigami H, Kazama S, Nozawa H, Kawai K, Hata K, Kiyomatsu T, Tanaka T, Tanaka J, Nishikawa T, Otani K, Yasuda K, et al. Breakthrough therapy for peritoneal carcinomatosis of gastric cancer: intraperitoneal chemotherapy with taxanes. World J Gastrointest Oncol. 2015; 7: 285-91. https://doi. org/10.4251/wjgo.v7.i11.285.

43. Kono K, Yong WP, Okayama H, Shabbir A, Momma T, Ohki S, Takenoshita S, So J. Intraperitoneal chemotherapy for gastric cancer with peritoneal disease: experience from
Singapore and Japan. Gastric Cancer. 2017; 20: 122-7. https://doi.org/10.1007/s10120-016-0660-y.

44. Kobayashi D, Kodera Y. Intraperitoneal chemotherapy for gastric cancer with peritoneal metastasis. Gastric Cancer. 2016; 3: 11-9. https://doi.org/10.1007/s10120-016-0662-9.

45. Rowinsky EK, Cazenave LA, Donehower RC. Taxol: a novel investigational antimicrotubule agent. J Natl Cancer Inst. 1990; 82: 1247-59.

46. Ma X, Huang M, Wang Z, Liu B, Zhu Z, Li C. ZHX1 inhibits gastric cancer cell growth through inducing cellcycle arrest and apoptosis. J Cancer. 2016; 7: 60-8. https:// doi.org/10.7150/jca.12973. 